\title{
Transition from Deflagration to Detonation in Layered Dust Explosions
}

\author{
M. Sichel, C. W. Kauffman and Y. C. Li \\ Department of Aerospace Engineering, \\ The University of Michigan, \\ Ann Arbor, Ml 48109
}

\begin{abstract}
Dust layers on the bottom of mine tunnels, on factory floors, or on the floors of grain elevator passages are the most frequent cause of highly destructive dust explosions. Typically, such layered dust explosions involve a high velocity, accelerating, turbulent flame which is fed by the dust layer and results in high destructive static and dynamic pressures. In some cases transition to detonation has been observed, and such explosions are the most destructive. Scientific studies of such layered dust explosions, conducted at the University of Michigan, are discussed.
\end{abstract}

\section{INTRODUCTION}

Dust explosions in coal mines motivated the carliest scientifie studics of combustion phenomena. Typically such explosions are caused by the layers of coal dust on mine floors but also have oceurred in many other industries involving the generation of dust, and of these explosions of grain clevators are, perhaps, the most common.

Typical organic dusts which are found in almost any industry have a specific explosion energy 3 to 5 times higher than military and commercial explosives, and many pharmaceutical and metallic dusts have specific explosion energies that are even higher. Consequently, accidental explosions of industrial dusts are usually devastating, and the dust flames which always accompary such explosions emit much more intense radiation than gaseous flames. For these reasons radiation burns and other injuries incurred in dust explosions can be scuere.

In recent times the number of a powder products has grown rapidly. especially in the food, textile, pharmaceutical, and metal industrics. Unfortunately many dust explosions continue to occur in connection with these industries. While data for many of these explosions remain undocumented, such as the 1991 flour explosion in a Detroit bagel bakery, some statistics are atvailable for the agricultural and agricultural product industries. Between 1976 and 1985 there have been 210 explosion incidents resulting in 143 deaths and 432 injuries. Some recent detailed accident statistics for grain ele- vators and grain handling facilities are as follows on a fiscal year basis: In 1988 there were 12 incidents resulting in 12 injuries and 8 deaths including the ADM Joliet IL disaster in which 5 died; In 1989 there were 10 incidents resulting in 5 injuries and 2 deaths; In 1990 there were a total of 18 incidents reported with 8 injuries and no deaths, while, through May 31, in fiscal 1991 there have been eight incidents resulting in 6 injuries and no deaths.

Although fires and explosions within the grain and grain products industry are specialized because of the involvement of grain dust, certain scientific results and technology are transferable to other fire and explosion situations such as occur in the chemical and petroleum industries. A detailed review of all accidents involving accidental fires and explosions in the United States during the last decade has recently been presented by Kauffman [I].

\section{ANATOMY OF LAYERED DUST EXPLOSIONS}

To have a dust explosion it is necessary that there be: ignition, fuel, oxidizer, mixing, and confinement. In layered dust as in other explosions all five elements must be simultaneously present. What distinguished layered dust explosions from others is the dominant role played by the entrainment and mixing of the dust layer with the surrounding gaseous oxidizer, usually air.

The elements of a typical layered dust explosion are illus- 
CHRONOLOGY OF A LAYERED DUST

EXPLOSION

Primary Explosion

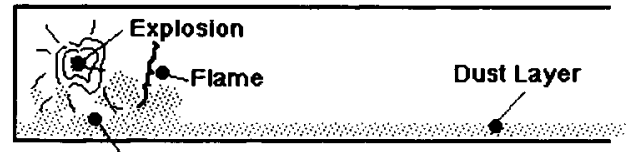

Dust Dispersal

Secondary Explosion
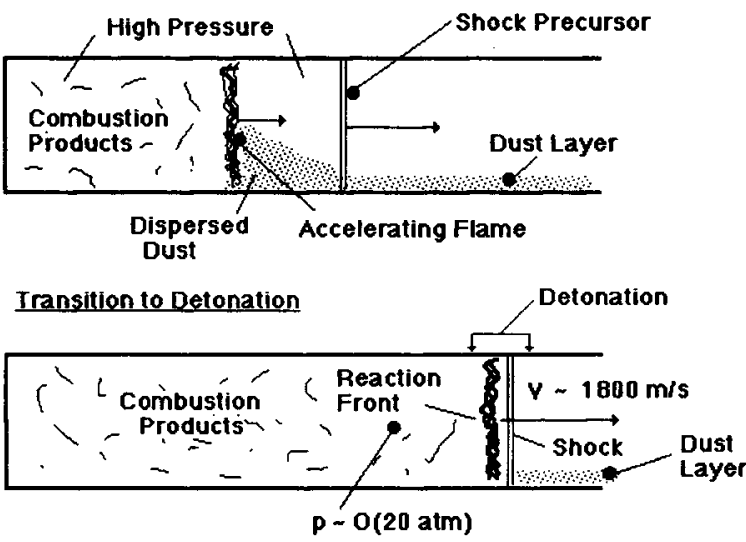

FIGURE 1. Elements of a Layered Dust Explosion.

trated in Figure 1. Ignition is usually started by a primary explosion which may be a consequence of electrical or mechanical sparks, a welding torch or numerous other sources. The primary explosion stirs up the settled layers of dust and ignites a dust flame which begins to propagate through the mine tunnel, grain elevator or production facility. Due to confinement and the fact that the primary explosion often occurs at the closed end of a tube or passage, as illustrated in Figure 1, the high temperature combustion products behind the flame cause the flame to accelerate which results in the formation of a precursor shock wave ahead of the flame. The dust lifted from the layer on the floor by the flow behind the shock provides further fuel for the accelerating flame. This process, called the secondary explosion, can result in the generation of high and very destructive pressures and gas velocities. Ultimately the flame-shock complex in secondary explosions may move at velocities on the order of $1000 \mathrm{~m} / \mathrm{s}$. Under some conditions this high speed flame and precursor shock become coupled together with a resultant transition to detonation. Such explosions are the most destructive and may generate pressures on the order of $20 \mathrm{~atm}$. Since these fronts move supersonically any venting to alleviate damage is relatively ineffective. During deflagration/detonation transition (DDT) pressure spikes with amplitudes as high as 60 atm have been observed.

The fundamental process governing these phenomena is the burning of the individual dust particles. The primary explosion then involves the propagation of a flame through a highly turbulent dust air mixture. The interaction between an accelerating flame, the shock precursor and the dust layer determine the severity of the secondary explosion and the likelihood that transition to detonation will occur. Of these phenomena, the secondary explosion is, perhaps, the most complex and studies of secondary layered dust explosions under controlled conditions are described below.

\section{EXPERIMENTAL MEASUREMENTS}

A Flame Acceleration Tube (FAT) has been used to study secondary explosions and is described in detail by $\mathrm{Li}$ et al [2].

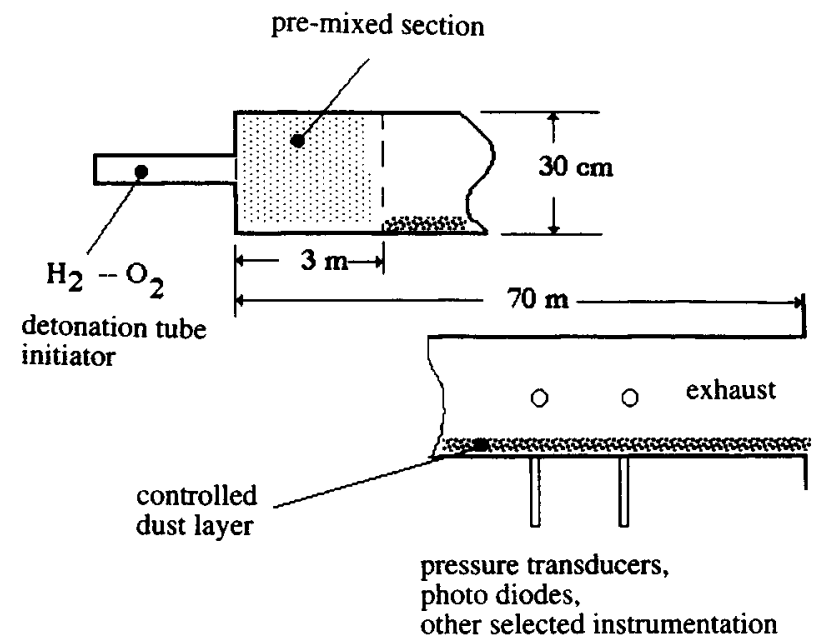

FIGURE 2. Schematic diagram of the Flame Acceleration Tube (FAT).

The FAT is a horizontal pipe with one end closed and the other open to ambient air. The FAT, a schematic diagram of which is shown in Figure 2, consists of a $70 \mathrm{~m}$ long steel tube with an inside diameter of $30 \mathrm{~cm}$. The FAT is instrumented with static pressure transducers, dynamic pressure transducers, and photo diodes at eight stations along the tube. A four-wavelength optical pyrometer is mounted near the end of the tube. Six pressure switches are distributed along the last $20 \mathrm{~m}$ of the FAT. The data acquisition system is composed of a 64 channel, $2 \mathrm{kHz}$ analog to digital converter-a LeCroy 8212A system, and an IBM Personal Computer AT. Four Kistler 603B1 pressure transducers are installed around the circumference at $90^{\circ}$ intervals at a distance of $60 \mathrm{~m}$ from the closed end. Tektronix 7D20 digital oscilloscopes are employed to record the signals from these Kistler transducers and from PCB 102A pressure transducers and photo diodes at the last two stations. The initiator assembly, as also shown in Figure 2, consists of a $2.44 \mathrm{~m}$ long and $5.08 \mathrm{~cm}$ inside diameter detonation tube and a three meter long V-channel within the FAT. The detonation tube, separated from the FAT by a Mylar diaphragm, is filled with an $\mathrm{H}_{2} / \mathrm{O}_{2}$ mixture.

A specially designed cart, equipped with a six liter dust pan, an auger, two motors (one driving the auger and the other the cart) and a fan, is used to travel inside the FAT and deposit the dust layer on the bottom of the FAT with the desired concentration, which can be adjusted by varying the auger speed. The cited dust loadings are taken as the nominal values based on the assumption that all of the dust in the layer is uniformly dispersed through the FAT prior to combustion. Generally this will not be the case; not all of the dust is necessarily dispersed and the distribution across the FAT will not be uniform. The actual dust distribution after dispersal can only be determined by careful concentration measurements, and these are not, so far, available. As will be evident from the results below, the dispersion process has a dominant influence of the flame acceleration and DDT.

Operationally, the dust layer is deposited into the main section of the FAT with the desired concentration by the cart. In the initiator section, cornstarch is laid along a $\mathrm{V}$ channel to produce concentrations of $500-600 \mathrm{~g} / \mathrm{m}^{3}$ after dispersion. The detonation tube is filled with a stoichiometric $\mathrm{H}_{2} / \mathrm{O}_{2}$ mixture with a pressure of $1 \mathrm{~atm}$ abs. High pressure air $\left(20^{-} \mathrm{atm}\right)$ is discharged through orifices in the $\mathrm{V}$-channel, suspending the dust in the initiator. After a $0.25 \mathrm{~s}$ delay, a glow plug ignites the gas mixture in the detonation tube, which then ignites the suspended dust cloud, leading to the combustion of the layered dust in the rest of the FAT. The energy release by the ignition process is negligibly small, compared with that of the later detonation process. 


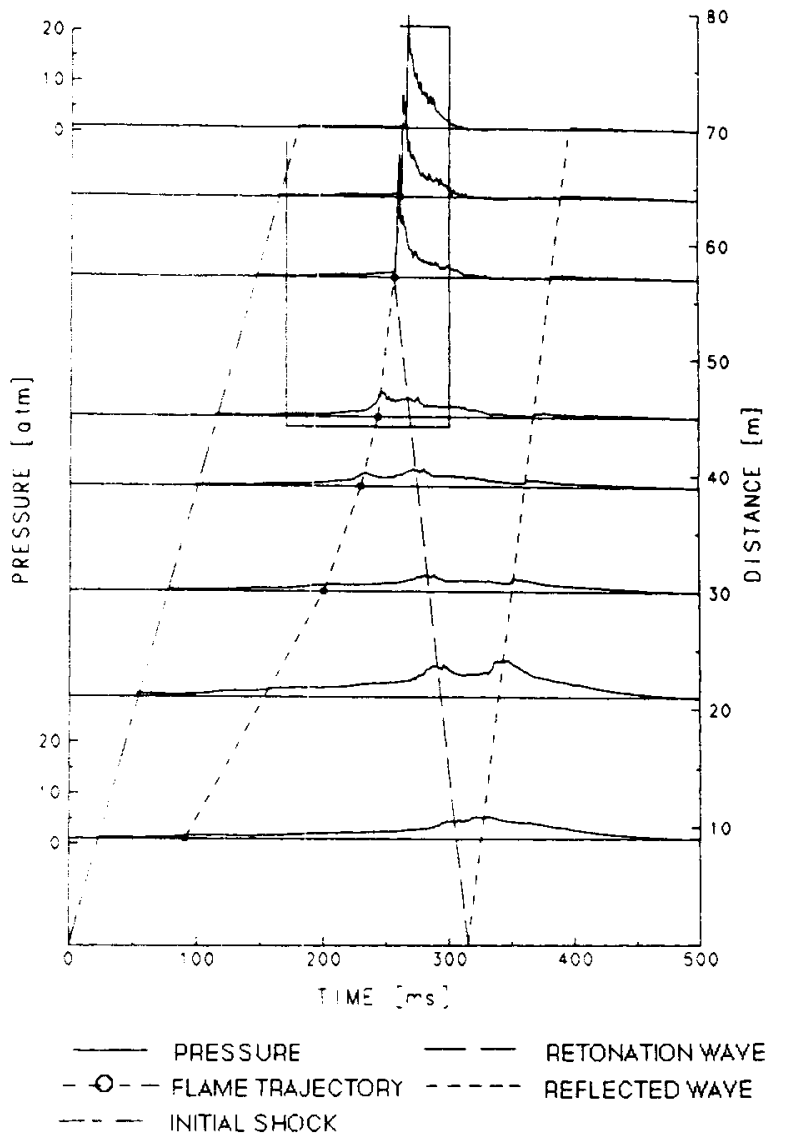

FIGURE 3. Pressure histories at eight measuring stations in the $70 \mathrm{~m}$ FAT showing flame trajectory (Ref. 2). Wheat dust layer, nominal concentrations:/ $\sigma=400 \mathrm{gm} / \mathrm{m}^{3}, 8<x<36 \mathrm{~m}$, $\sigma=300 \mathrm{gm} / \mathrm{m}^{3}, 33<x<67 \mathrm{~m}$.

\section{RESULTS OBTAINED FROM THE FLAME ACCELERATION TUBE}

\section{Pressure Histories}

Pressure histories measured by $\mathrm{Li}$ et al [2] at different distances from the closed end of the FAT. as illustrated in Figure 3. indicatc that detonation or quasi-detonation can be achieved in initially layered grain dust with ambient air as oxidizer. Figure 3 shows the variation of pressure with time at various stations along the FAT and the trajectory of the flame propagating down the FAT, based on photo diode measurements at different measuring stations. It can be seen in Figure 3 that the flame front accelerates rapidly in the second hall of the FAT. while pressure waves associated with the flame coalesee into strong shocks. A sudden increase of maximum pressure can be observed between $x=45$ and $64 \mathrm{~m}$ from approximately 7 to $26 \mathrm{~atm}$ and an increase in flame velocity from approximately 400 to $1400 \mathrm{~m} / \mathrm{s}$. A wave originating from this location travels back to the closed end of the FAT it a nearly constint velocity, at the local speed of sound and when it reaches the closed end of the FAT a reflected wave energes traveling toward the open end, also at the local speed of sound. The wave traveling backwards is very typical of DDT in gascous detonations, and was first identified and named retonation wave by Dixon nearly a century ago. An explosion occurred between $x=45$ and $64 \mathrm{~m}$, and this is the "Explosion within an explosion" noted by Urtiev and Oppenheim [3] which almost always appears during DDT. There are also significant differences between the structure of gaseous and helerogeneous detonations. Thus Zhang and

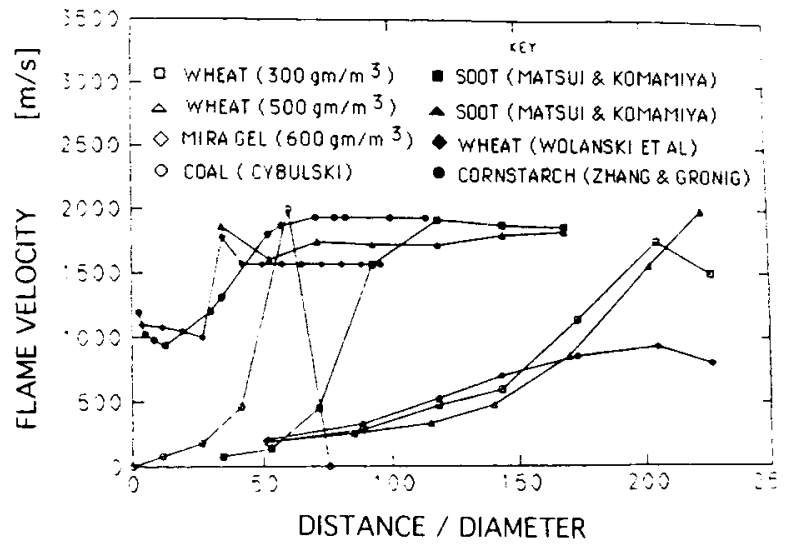

FIGURE 4. Flame propagation velocity as a function of $x / d$, the ratio of distance to tube diameter Results shown: Wolanski et al. [6], corn starch pre-dispersed in air, $\sigma=500 \mathrm{gm} / \mathrm{m}^{3}, d=13 \mathrm{~cm}$; Zhang and Groenig [4], corn starch pre-dispersed in $O_{2}, \sigma=500 \mathrm{gm} / \mathrm{m}^{3}, \mathrm{~d}=$ $14.1 \mathrm{~cm}$; Matsui and Komamaiya [7], soot coating in $O_{2}$, $d=2.8 \mathrm{~cm}$; Cybulski [8], coal dust, pre-layered in air, $d$ (equivalent) $=265 \mathrm{~cm}$. From Ref. 5 .

Groenig [4] observed a spin like structure in detonations propagating through a pre-mixed cloud of corn starch and oxygen over a wide range of concentrations in contrast to very reactive gaseous fuels for which such structures only occur in mixtures very close to the detonation limit. It should be noted that for less reactive gascous explosives such as methane spin also is observed over a wide range of mixture ratios.

\section{Transition Distance}

The distance for transition to detonation is one of the most important parameters governing DDT and is in many cases an indicator of the likelihood that transition to detonation will occur. Detonation is unlikely in tubes or channels shorter than this distance. The main parameters governing this distance are the tube dimension and geometry, the wall roughness, the nature, strength and location of the ignition source, the boundary conditions, i.e. closed vs. open ended tubes, the heat of combustion and the reaction kinetics of the fuel. These parameters contribute to the level of turbulence, and the shock flame interactions which are two of the main flame acceleration mechanisms leading to transition. In order to compare transition distances for dust detonations, measured under various conditions the variation of flame velocity with distance normalized by tube diameter as measured by several investigators and in the FAT is shown in Figure 4 taken from [5]. Transition to detonation is indicated when the flame propagation velocity reaches the detonation velocity which is generally on the order of 1500 to $2000 \mathrm{~m} / \mathrm{s}$ for organic dusts.

For comparison the results of the studies of DDT in hetcrogeneous explosions of Wolanski ct al. [6], Zhang and Groenig [4], Matsui and Komamiya [7], and Cybulski [8] are also shown in Figure 4. A description of experimental facilities and test methods used by these authors are presented in Table 1. Wolanski et al. [6] used a $13 \mathrm{~m}$ long and $13 \mathrm{~cm}$ i.d. vertical tube, and Zhang and Groenig [4] used a $17.4 \mathrm{~m}$ long and $14.1 \mathrm{~cm}$ i.d. horizontal tube. Pre-suspended dust and strong shock initiation were used in both studies. while Zhang and Groenig used pure oxygen to enhance the combustion process. Matsui and Komamiya [7] used a $5.2 \mathrm{~m}$ long and 2.8 $\mathrm{cm}$ i.d. tube coated with soot particles formed from the burning of acetylene. Technically, this work does not belong to the category of dust combustion, because a) the sizes of soot particles are in range of 5 to 10 nanometers, while small 
Table 1 Test Conditions for the Flame Propagation Data Shown in Figure 4

\begin{tabular}{|c|c|c|c|c|c|}
\hline Investigation & $\begin{array}{r}\text { Tube } \\
\text { Length } \\
{[\mathrm{m}]}\end{array}$ & $\begin{array}{r}\text { Tubc } \\
\text { Diameter } \\
{[\mathrm{cm}]}\end{array}$ & Initiation & $\begin{array}{l}\text { Loading } \\
\text { Pattern }\end{array}$ & Oxidizer \\
\hline This Study & 71 & 29.85 & Self & Pre-layered & Air \\
\hline Matsui and Komamiya [22] & 5.2 & 2.8 & Both & Film Coated & Oxygen \\
\hline Wolański et al. [18] & 13 & 13 & Direct & Pre-suspended & Air \\
\hline Zhang and Grönig [19] & 17.4 & 14.1 & Direct & Pre-suspended & Oxygen \\
\hline
\end{tabular}

"The maximum height of the gallery is chosen as characteristic length.

conventional dust particles of interest in most dust explosions are generally in the range of $5-400 \mu \mathrm{m}$ in diameter, and b) these soot particles contained a large proportion of hydrogen. Cybulski [8] studied coal dust flame propagation in a $400 \mathrm{~m}$ long gallery in an experimental mine. The maximum height of the gallery $(2.65 \mathrm{~m})$ was chosen as the characteristic length in determining the normalized distance $x / d$. The dust was layered on the floor and shelves in the gallery for a distance of $200 \mathrm{~m}$. The ignitor was located in the middle of the $400 \mathrm{~m}$ long gallery so that the flame, essentially, propagated from an open toward a closed end, thus providing a very different boundary condition from the other investigations compared here.

From Figure 4 it can be seen that stable detonations propagating at a constant velocity were achieved using direct or shock initiation by Wolanski et al. [6], Zhang and Groenig [2], and Matsui and Komamiya [7] in a distance on the order of 50 tube diameters. Matsui and Komamiya [7] also achieved a stable detonation with self initiation but the transition distance was doubled to about 100 tube diameters. Detonation velocity also was reached by Cybulski $[8]$ in pre-layered dust at a distance of about 50 characteristic lengths after which the velocity dropped to zero because of the conditions of the experiment.

The flame velocity in the FAT for wheat with a concentration of $\sigma=300 \mathrm{gm} / \mathrm{m}^{3}$ increases to about $1750 \mathrm{~m} / \mathrm{s}$ until $\mathrm{x} / \mathrm{d} \approx 210$ after which it decelerates to $1500 \mathrm{~m} / \mathrm{s}$ at the end of the FAT. For the richer flame with $\sigma=500 \mathrm{gm} / \mathrm{m}^{3}$ the velocity accelerates continuously until it reaches a value of about $2000 \mathrm{~m} / \mathrm{s}$ at the end of the FAT. In the case of Mira Gel dust the flame reaches a constant velocity of about $900 \mathrm{~m} / \mathrm{s}$ at $\mathrm{x} / \mathrm{d} \approx 170$ and this wave can be considered to be a quasi detonation rather than a regular, full fledged detonation. While the pressure profiles and flame trajectories in Figure 3 , and others like it ( $\mathrm{Li}$ et al., [2], Li, [9]) indicate that transition to detonation has occurred, it is not clear from the results shown in Figure 4 that this layered dust detonation is stable and would continue to propagate at a constant velocity or whether it would propagate as a galloping detonation or possibly extinguish. A tube much longer than the FAT would be required to establish the behavior of the layered dust detonation after DDT has occurred. However, in any case, damage in an accidental explosion with these characteristics would be extensive.

It is, perhaps, questionable to compare results at the same value of the normalized distance $x / d$ since the boundary conditions for each of the experiments described above are different. However, the results do indicate that the transition distance for layered dust detonations is about twice that for detonations propagating through pre-dispersed dust, probably because reaction between the dust particles and the oxidizer must be preceded by the relatively slow dust entrainment process. The comparison of results in Figure 4 indicates that DDT is favored by pre-mixing of the dust and oxidizer, direct or blast vs. self initiation, and enrichment of air by oxygen or replacement by pure oxygen.

\section{The Effect of Dust Moisture Content and Layer Geometry}

Humidity and the frequency of dust explosions in industry are closely related. Statistics on dust explosion accidents in the United States from 1979 to 1986 [10] show that an overwhelming majority of such explosions occurred in the winter months (November through February, October through March for the high latitude states), and in inland areas (100 miles or farther from coast lines). Low humidity in these months and areas certainly contributes to the causes of dust explosions in the grain industry, since humidity of the ambient air directly affects the moisture content of dusts. During the experimental study of explosions in the FAT, a similar situation was experienced, i.e., most of the runs that resulted in DDT were observed during the winter months rather than in the summer (especially in July and August), since the dust layers were in direct contact with the ambient air. The pressure histories and flame trajectories for two runs with Mira Gel dust are shown in Figure $5[I /]$. All conditions are identical except that one run used dry dust when the atmospheric

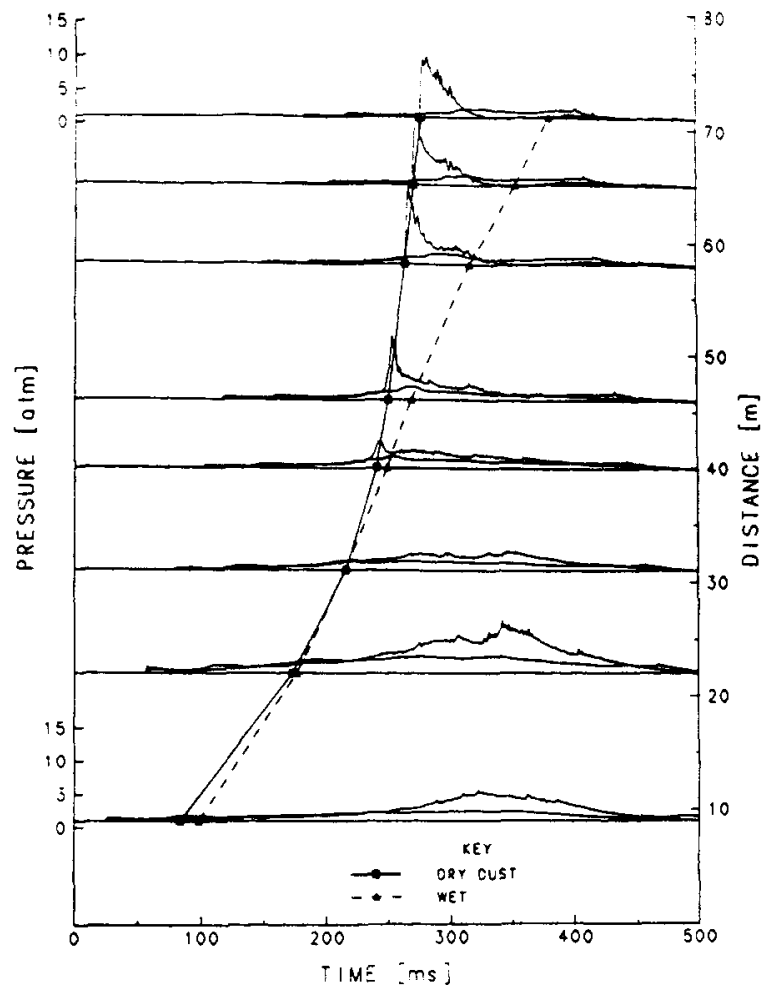

FIGURE 5. A comparison of pressure histories and flame trajectories for wet and dry Mira Gel. Concentration $\mathbf{5 0 0}$ $\mathrm{gm} / \mathrm{m}^{3}$, initiator concentration $500 \mathrm{gm} / \mathrm{m}^{3}$. Reproduced from Combustion and Flame 100, pp. 505-515 (1995) (C) 1995 Elsevier Science, Inc. 


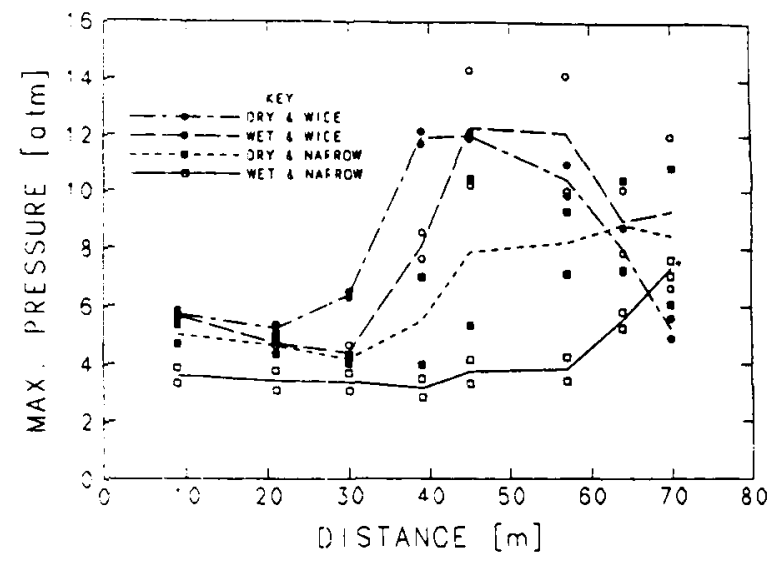

FIGURE 6. Maximum pressure development for four different combinations of dry, moist, wide and narrow dust layers. Note that the curves represent the averages of two different data points for the same experimental condition. Fuel: cornstarch, concentration $500 \mathrm{gm} / \mathrm{m}^{3}$, bead length $51 \mathrm{~m}$. Reproduced from Combustion and Flame 100, pp. 505-515 (1995) (c) 1995 Elsevier Science, Inc.

humidity was low, while the other used dust under high humidity conditions. The cifferences between these two runs are striking. Both dry and wet runs produced very similar pressure waves and flame trajectories in the early stage $(x<$ $31 \mathrm{~m})$. In fact. the flame velocity of the wet run for $9<x<21$ $\mathrm{m}$ is even slightly higher than that of the dry run. However. the combustion wave of the dry run continued to accelerate through the rest of the FAT. while the counterpart in the wet run decelerated and. as a consequence, generated much lower pressures than the dry run. Figure 5 thus demonstrates, at least qualitatively, the irmportance of dust moisture content on the combustion process.

The effects of moisture content on the maximum pressure as a function of distance along the FAT are shown in Figure 6 for cornstarch dust with $1 \%$ in weight Cab-O-Sil amorphous fumed silica additive [11] with a nominal dust loading of $500 \mathrm{gm} / \mathrm{m}^{3}$. The length of the dust layer was $51 \mathrm{~m}$. The curves represent the average value of two different runs at the same conditions. Results are shown for both wide and narrow dust layers as discussed in more detail below; however. for each class of layer the moist dust explosions generated significantly lower pressures than the dry dust.

For pre-layered dust combustion, unlike pre-suspended dust combustion, dust particles must first be entrained into and mixed with the ambient oxidizing atmosphere. Ordinarily, the overwhelming majority of dust particles do not exist individually but as agglomerates of many particles. The moisture content strongly affects the cohesiveness of these agglomerations. so that the convective flow induced by the compression (or shock) waves ahead of the deflagration more readily breaks up the drier dust agglomerations than those with the high moisture content. The moisture inside the dust also absorbs a certain amount of heat during vaporization and devolatilization, and this also may diminish the intensity of the combustion process. High moisture content thus adversely affects the mixing process of dust and air which explains the results shown in Figures 5 and 6 .

Since dispersion plays a key role in layered dust explosions. the geometry of the dust layer must also be an important parameter: therefore, the effect of dust layer thicknesses and width was investigated. For this purpose layered explosions were initiated in the FAT for two dust layers with different thicknesses and widths but with the same nominal concentration. The thicknesses of the wide and narrow layers were of the order of $0.5 \mathrm{~mm}$ and $5 \mathrm{~mm}$, respectively. Due to the identical concentrations for both, the thin layer provides a wider coverage, on the order of $50 \mathrm{~cm}$, over the inside wall of the FAT. The width of the thick layer was approximately $5-8 \mathrm{~cm}$.

As can be seen in Figure 6, moist dust with a narrow layer produces the weakest combustion among all four combinations. Dry dust with a wide layer resulted in the fastest pressure development. This is a very reasonable result since dry dust. as already noted above, promotes more intense combustion than moist dust. and because the wider layer exposes more dust particles to the dispersing convective flow above the layer. Among the other two combinations. moist dust with a wide layer resulted in faster pressure development and produces higher pressure than dry dust with a narrow layer suggesting that between the factors of moisture content and layer thickness the latter seems to be more important.

Another interesting result is that the combination that produces the fastest pressure rise is also the one for which the pressure drops most rapidly toward the end of the FAT. Thus, the pressure for the dry dust with a wide layer peaks at $\mathrm{x}=39 \mathrm{~m}$ and then drops very rapidly, while that for moist dust with a narrow layer continues to increase to the end of the FAT. The fact that the pressure is still increasing beyond the end of the dust layer at $x=51 \mathrm{~m}$ suggests that the slower burning rates enable some portion of the dust to be carried downstream by the convective flow and to be hurned there.

From the above observations it can be concluded that for the same nominal concentration, wide layers are more supportive of dust combustion (explosion) processes than narrow layers. Because of the greater exposed area of the wide layers to the convective flow, more dust particles can be entrained into the ambient air; enhancing the mixing process between the dust particles and the oxidizer. For narrow layers, the mixing and combustion processes are probably "localized" near the bottom of the FAT. Hence, a large portion of the FAT cross section and the oxidizer it contains is not-utilized and this non-uniformity will certainly have an adverse affect on combustion.

\section{Influence of Dust Characteristics on Peak Explosion Pressures}

The main experimental results for the four different dusts considered in the layered dust explosion studies are summarized in Table 2. Because of the extreme complexity and unpredictable nature of the dust explosion processes, the experiments are not always repeatable and the data scatter over a relatively wide range. The data for corn dust were collected for a path length which was limited to $39 \mathrm{~m}$, and, hence, it is inappropriate to compare them with the data of other dust types. Detonations were not observed in the corn dust runs. evidently because the path lengths were too short to permit DDT.

Among the conditions affecting flame acceleration, the moisture content and width of the dust layer (discussed above) play very important roles. In addition, the origin and physical nature of the particular dust are important factors affecting explosibility. As can be seen in Table 2, cornstarch exhibits weaker explosive parameters than Mira Gel, although both dusts possess the same chemical composition. Furthermore, by observing the processes of flame acceleration, it was found that DDT was more likely to occur when the flame front is far behind the initial precursor shock for then the flame will propagate into an already well dispersed dust cloud. This conclusion is supported by the results of runs with voids inserted in the dust layer. These voids cause the flame to decelerate in the front part of the FAT and hence leave sufficient time for the initial shocks and pressure waves to entrain the layered dust. The flames which follow greatly benefit from this well-dispersed dust cloud and accelerate more rapidly in the rear part of the FAT.

As can be seen in Table 2, Mira Gel explosion parameters reach their maximum values at a concentration of $500 \mathrm{~g} / \mathrm{m}^{3}$ 
Table 2 Layered Explosion Data for Various Dusts

\begin{tabular}{|c|c|c|c|c|c|c|}
\hline o & $V_{i}$ & $V$ & $D$ & \multirow{2}{*}{$\begin{array}{l}T_{\max } \\
{[\mathbf{K}]}\end{array}$} & $P$ & $\left(P_{\max }\right)$ \\
\hline$\left[\mathrm{g} / \mathrm{m}^{7}\right]$ & & {$[\mathrm{m} / \mathrm{s}]$} & & & \multicolumn{2}{|c|}{ [atm] } \\
\hline \multicolumn{7}{|c|}{ Corn $^{i 1}$} \\
\hline 500 & & & & $\sim 1700$ & -5 & 10 \\
\hline \multicolumn{7}{|c|}{ Cornstarch" } \\
\hline 500 & $1078-1330$ & $1085-11300$ & $1050-1200$ & $1640-1910$ & -19 & 26 \\
\hline \multicolumn{7}{|c|}{ Mira Gel } \\
\hline 250 & 925 & $\sim 1200$ & $\sim 1150$ & $1670-1850$ & $\sim 9$ & \\
\hline 300 & 1200 & 1250 & $1150-1200$ & $\sim 1700$ & & -28 \\
\hline 350 & 1300 & 1370 & $1250-1300$ & $\sim 1800$ & -20 & 29 \\
\hline 400 & $1000-1368$ & $1170-1368$ & $1100-1300$ & $1620-1760$ & $14-19$ & 28 \\
\hline 500 & $1368-1714$ & $1520-1714$ & $1350-1650$ & $1700-1730$ & $\sim 21$ & 35 \\
\hline \multicolumn{7}{|c|}{ Wheat } \\
\hline 250 & 1070 & 1280 & 1200 & 1670 & 23 & 40 \\
\hline 300 & $1470-1790$ & $1510-1790$ & $1420-1700$ & $\sim 1800$ & 26 & 62 \\
\hline 350 & $>1400$ & $1365-1720$ & $1250-1650$ & $\sim 1800$ & 26 & 55 \\
\hline 400 & 1625 & $1280-1670$ & $1200-1550$ & $1700-1800$ & 24 & 45 \\
\hline 450 & 1395 & 1395 & 1300 & -1600 & 24 & 35 \\
\hline 500 & $1200-1400$ & $1160-1250$ & $1100-1180$ & $1680-1800$ & $16-21$ & 32 \\
\hline \multicolumn{7}{|c|}{ Wood } \\
\hline $400^{\mathrm{c}}$ & $1200-1600$ & $1200-1600$ & $1050-1510$ & $1600-1800$ & 20 & 46 \\
\hline $400^{d i}$ & $1480-1775$ & $1480-1775$ & $1400-1700$ & $1600-1800$ & 26 & 88 \\
\hline
\end{tabular}

Detonation not ohserved because of path length $=39 \mathrm{~m}$.

" $1 \mathrm{C} / \mathrm{in}$ weight Cab-O-Sil amorphous fumed silica dust added.

CDust size $d<150 \mu \mathrm{m}$.

" $d<125 \mu \mathrm{m}$

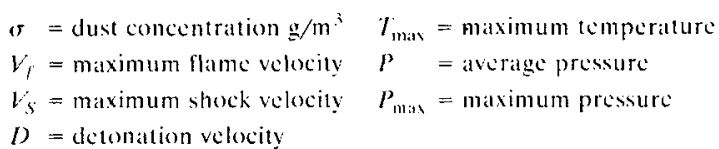

with a detonation velocity $D=1650 \mathrm{~m} / \mathrm{s}$ and a maximum pressure $\mathrm{P}_{\text {max }}=35 \mathrm{~atm}$. However the differences as concentrations range from $250-500 \mathrm{gm} / \mathrm{m}^{3}$, do not seem very significant. Wheat dust detonations are stronger than those observed in cornstarch and Mira Gel with maximum pressures and detonation velocities as high as 62 atm and $1700 \mathrm{~m} / \mathrm{s}$. Wood flour exhibits a maximum pressure of $88 \mathrm{~atm}$, one of the highest ever reported in dust detonations, and a velocity of $1700 \mathrm{~m} / \mathrm{s}$ for particle diameters, $d<125 \mu \mathrm{m}$. This pressure peak was observed near the location where DDT occurs. As already noted above, such pressure spikes are often observed during DDT in gaseous detonations as well and appear to be a consequence of the "explosion within an explosion," discussed above, which is often associated with transition. Prior to this study the highest pressure and detonation velocity were reported by Gardner et al. [12] at $-81.5 \mathrm{~atm}$ and $2850 \mathrm{~m} / \mathrm{s}$, respectively, in pre-dispersed coal dust. Examining this data, it appears that this high pressure and velocity were apparently also recorded in the neighborhood of the DDT point.

From the wood flour data, it can be seen that the dust with smaller particle size definitely produces a stronger detonation. Since smaller particles require less time to reach the autoignition temperature, i.e., have a shorter ignition delay time they, as a group, exhibit stronger detonations; however, this trend does not necessarily continue with decreasing particle size. As the particle size continues to decrease for a given dust loading the particle surface area available for ah- sorption of heat from the surrounding medium increases. As a result, for very small particles, there may, initially, be a decrease in the ambient temperature and consequently an increase in the ignition delay time. This phenomenon has been supported by experimental data as well as by theoretical calculations for RDX particles for which the optimum diameter for minimum ignition delay was calculated by Lee et al. [13] to be in the range of $6-10 \mu \mathrm{m}$. However, the dusts tested in this study all are above this size range so that the smallest size $(\mathrm{d}<125 \mu \mathrm{m})$ turned out to be the most detonative.

It is interesting that wood flour and wheat dust demonstrated a stronger detonability than cornstarch or Mira Gel. For explosions of pre-dispersed dust in a constant volume enclosure of volume $V$ the explosion rate constant for dust, $K_{\text {Si }}$, defined as:

$$
K_{s t}=\left(\frac{d P}{d t}\right)_{\max } V^{1 / 3}
$$

is often used as a measure of the "explosibility" of a given dust-oxidizer mixture. It is found that the value of $K_{s t}$ is approximately the same for wood flour, corn starch and wheat dust in contrast to the observed "explosibility" of these dusts in layered explosions. This difference can be explained by the fact, already noted, that in pre-layered dust detonations the dominant factor is the dust/oxidizer mixing process. The physical shape and specific gravity of wood flour and wheat 


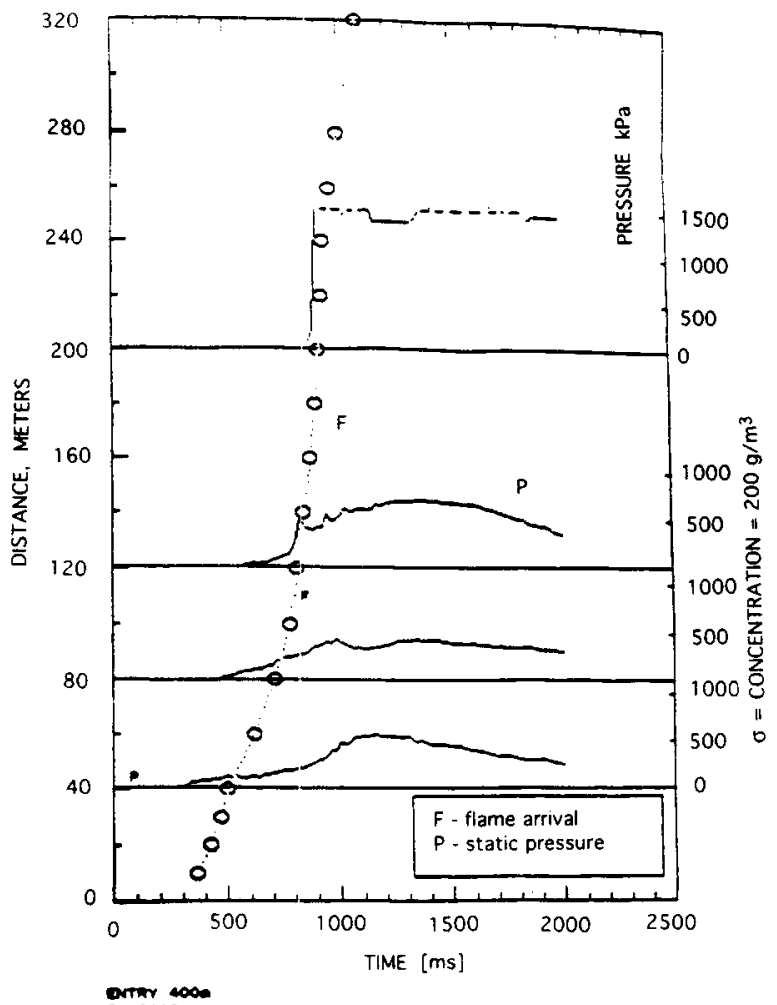

$\operatorname{Din}_{2+\infty}+\infty 000$

FIGURE 7. Pressure history from The Mine Barbara. Concentration $200 \mathrm{gm} / \mathrm{m}^{3}$. From Ret. 14.

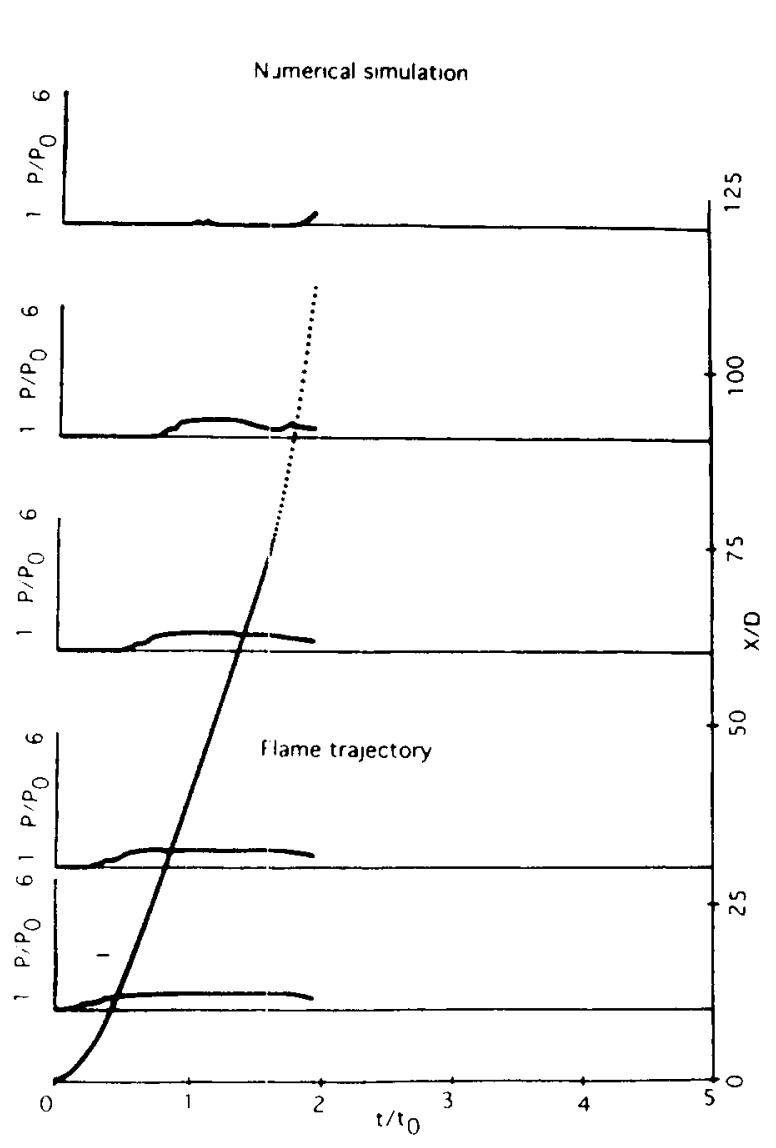

dust particles enable them to be more effectively entrained with ambient air, providing a suitable concentration to support flame propagation. The $K_{\psi}$ value are usually measured in a constant volume combustor in which the dusts tested have been very well mixed with the oxidizers, before they are ignited.

\section{Scaling of Experimental Results}

In almost all laboratory scale explosion experiments the question of scaling the results to larger or full scale facilities always arises. This is certainly true for the FAT which has an inner diameter of only $30 \mathrm{~cm}$. Layered dust explosions also have been studied in The Mine Barbara in Poland. In particular, the explosion of wheat dust layers was investigated in a gallery of this full scale mine which is $3 \mathrm{~m}$ wide, $2.65 \mathrm{~m}$ high and $400 \mathrm{~m}$ long. This facility has been described in detail by Wolanski [ 14]. An example of the pressure histories recorded at different distances from the closed end of this gallery is shown in Figure 7. The results are at least qualitatively similar to the pressure histories from the FAT shown in Figure 3. In this particular case transition to detonation occurred between 120 and $200 \mathrm{~m}$ from the closed end of the gallery with maximum pressures on the order of $1.5 \mathrm{MPa}$. This value of the peak pressure is of the same order as that observed in the FAT when DDT occurred. These full scale results do indeed suggest that the data obtained in the FAT experiments are relevant to larger facilities.

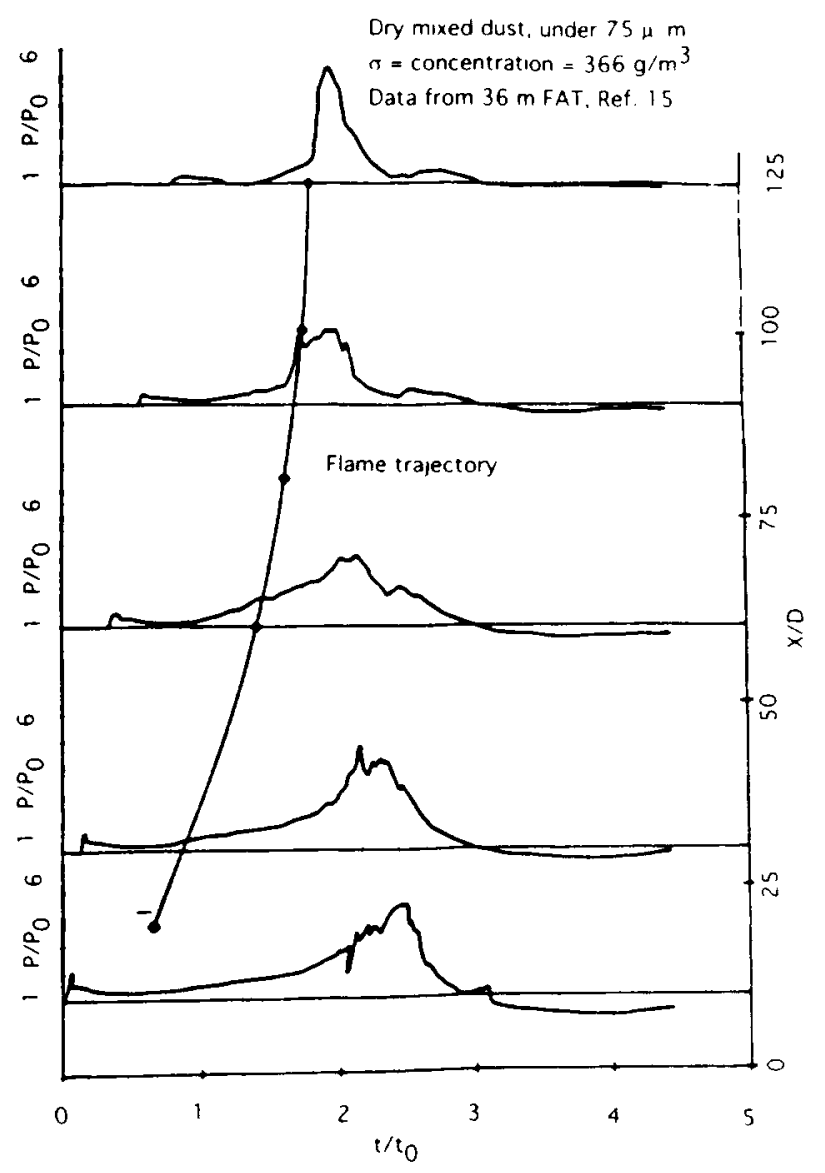

FIGURE 8. Computed and measured variation of the pressure and flame position as a function of normalized time (normalized by time of shock wave passage through the FAT). From Ref. 16. 


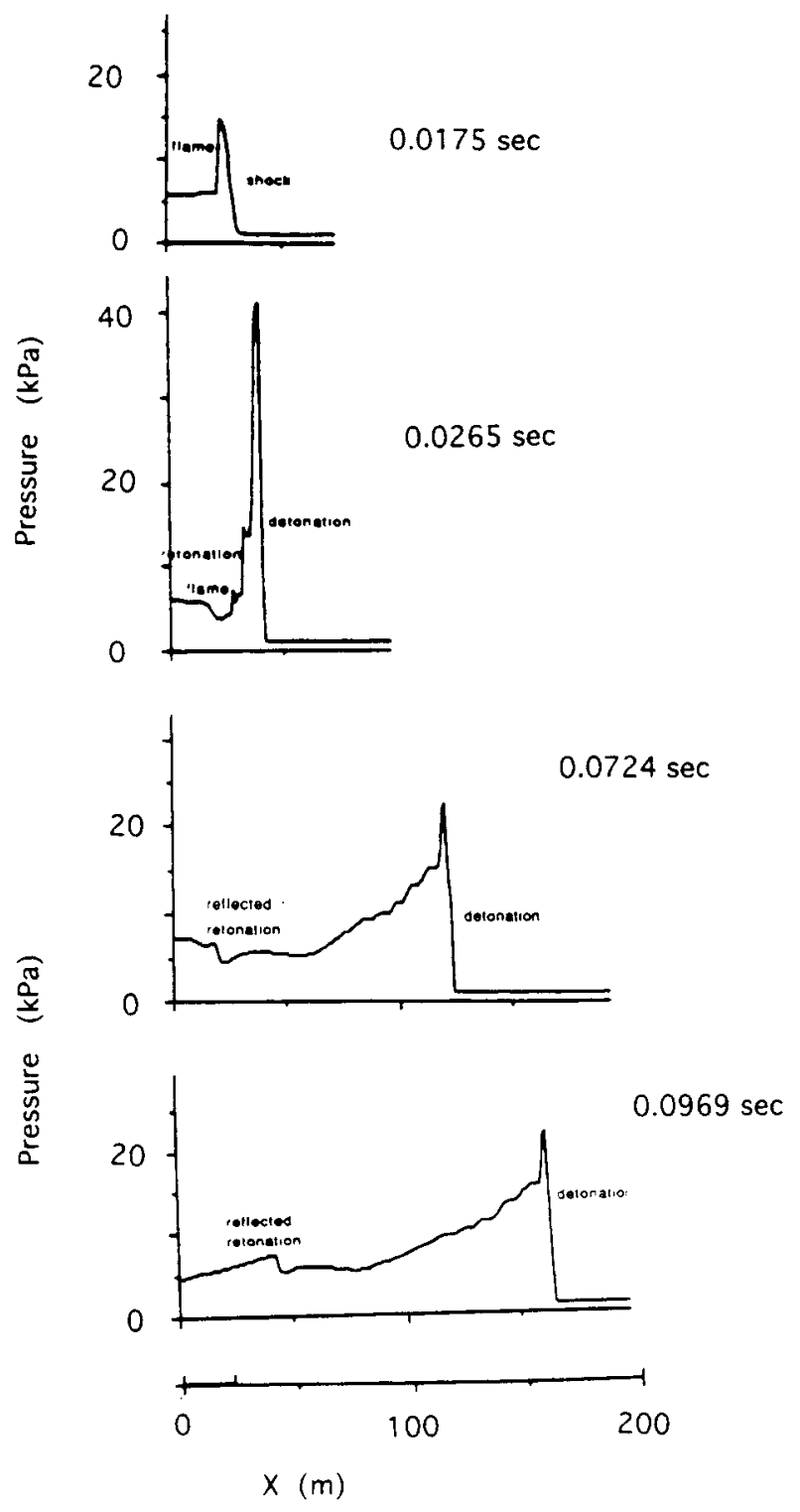

FIGURE 9. Computed pressure profiles behind a shock wave driven by an accelerating flame. From Ref. 17.

\section{MODELING STUDIES}

A number of modeling studies of various aspects of layered dust explosion have been conducted. This process involves many complex nonlinear and unsteady phenomena. The most important and difficult phenomena to model are the entrainment of the dust from a surface by the boundary layer flow, the succeeding formation of the dust-air mixture, and the coupling of the burning velocity with the intensity and scale of the turbulence ahead of the flame. In an early attempt to model such explosions, the Chi and Perlee code for flame propagation in ducts was applied to the layered dust explosion problem by Srinath [15]. While these calculations reproduced the flame trajectories reasonably well, the computed pressure variation did not agree with the experimental results, and the dust dispersion process was not taken into account.

To improve this model Chang, et al. [16] incorporated a model of dust dispersion developed by Mirels, and the turbulerit combustion model of Clark and Smoot in the Chi-Pcrlee code. Calculations were made for grain dust with $49 \mu \mathrm{m}$ diameter particles and a dust layer loading of $0.5 \mathrm{~kg} / \mathrm{m}^{3}$. The calculated pressure histories at different downstream loca- tions are shown in Figure 8(a), while experimental results obtained under similar conditions are presented in Figure 8 (b). It can be seen that the initial pressure rise and flame trajectory are comparable but the subsequent pressure rise observed in the experiments was not reproduced by the theory.

The difficulty is that both the Chang and Srinath models ignore the possibility of reaction between the flame front and the shock propagating ahead of it. To investigate this effect Lee and Sichel [17] developed a one dimensional numerical simulation of an accelerating flame propagating through a gaseous fuel oxidizer mixture in which the possibility of an explosion between the leading shock and flame is taken into account. Four pressure profiles at different times, computed using this model, are shown in Figure 9. The first frame shows the pressure rise across the leading shock followed by a pressure drop across the flame before there has been any reaction between the flame and the shock. The occurrence of an intense explosion leading to very high pressures similar to those observed in the experiments is evident in the following irame. The model thus reproduces the "explosion within an explosion" observed during transition to detonation. The succeeding frames show the development of a steady state detonation pressure profile. This model does not account for the dust dispersion nor does it explain the factors determining flame acceleration, and these are subjects for future research. One dimensional modeling studies of the structure of a dust detonation which take two phase flow and the individual particle reactions into account have also been conducted $[18]$.

\section{CONCLUSIONS}

Transition from deflagration to detonation has definitely been observed in layered dust explosions. DDT in layered dust explosions is favored by a low moisture content, a large dust layer area exposed to the convective flow behind the leading shock, and physical characteristics of dust particles which favor entrainment. The importance of these factors indicates that pre-layered dust explosions are dominated by the dust/air mixing process. The strong detonability of wood and wheat dust compared to other, less entrainable dusts also reinforce this conclusion. While the explosion rate constant $K_{s}$ can be used to evaluate the explosibility of dust dispersed in constant volume containers, it does not appear to be an appropriate indicator of "explosibility" or detonability in layered dust explosions. Comparison to full scale experiments in the experimental mine Barbara suggest that the results obtained from the FAT are, at least qualitatively applicable to large scale facilities. Modeling studies have so far been able to reproduce only some aspects of layered dust explosions; therefore, much remains to be done in this area.

\section{ACKNOWLEDGMENT}

Many of the results reported here were obtained in the research sponsored by the National Institute of Occupational Safety and Health of the U.S. Department of Health and Human Services under Grant No.: OH01122-09.

\section{LITERATURE CITED}

1. Kauffman, C. W., Disasters Resulting from Fire, Explosion, and Reactive Materials - A Survey of the Last Decade of Incidents Occurring in the United States. Major Industrial Accidents: Lessons to be Learned. Paris, France, (September 20-21, 1990). 
2. Li, Y. C., C. G. Alexander, P. Wolanski, C. W. Kauffman, and M. Sichel, Experimental Investigations of Accelerating flames and Transition to Detonation in Layered Grain Dust. In: Kuhl A. L., et al. (eds) Progress in Astronautics and Aeronautics. AIAA, New York, Vol. 154, pp. 170-184 (1993).

3. Urtiew, P. A., and A. K. Oppenheim, Pro. Roy. Soc. Lond., A295:13-28 (1966).

4. Zhang, F., and H. Groenig, Transition and Structure of Dust Detonations. In: Borissov, A. A. (ed) Dynamic Structure of Detonation in Gaseous and Dispersed Media. Kluwer Academic, Boston, pp. 157-213 (1991).

5. Li, Y.-C. A. S. Harbaugh, C. G. Alexander, C. W. Kauffman, and M. Sichel, "Deflagration to Detonation Transition Fueled by Dust Layers," paper presented at the 14th Colloquium on the Dynamics of Explosions and Reactive Systems, Coimbra, Portugal (August 1993).

6. Wolanski, P., W. Sacha, and M. Zelesinski, Proceedings of the Fourth International Colloquium on Dust Explosions, Porabka-Kozubnik, Poland, pp. 355-370 (1990).

7. Matsui, H., and K. Komamiya, An Experimental Study of Soot Film Detonations. In: Bowen, J. R. et al. (eds) Progress of Astronatutics and Aeronautics. AIAA, New York. Vol. 106, pp. 559-570 (1986).

8. Cybulski, W., Coal Dust Explosions and their Suppression. Forcign Scientific Publications Department of the National Center for Scientific, Technical, and Economic Information. Warsaw Poland (1975).

9. Li, Y., I. Lflagration to Detonation Transition Fueled by Dust Layers. Ph.D. thesis, University of Michigan (1993).

10. Kauffman, C. W., in Indusrial Dust Explosions, ASTM STP 958 (K. L. Cashdollar and M. Hertzberg, Eds.), American Society for Testing and Materials, Philadelphia, p. 243 (1987).

11. Li, Yu-Chen, C. W. Kauffman, and M. Sichel, "An Experimental Study of Deflagration to Detonation Transi- tion Supported by Dust Layers," Combustion and Flame, 100, pp. 505-515 (1995).

12. Gardner, B. R., R. J. Winter, and M. J. Moore, “Explosion Development and Deflagration-To-Detonation Transition in Coal Dust / Air Susensions" Twenty-First Symposium (International) on Combustion, The Combustion Institute, Pittsburgh, pp. 335-343 (1986).

13. Lee, F. P., C. W. Kauffman, M. Sichel, and J. A. Nicholls, "Detonability of RDX Dust in Air / Oxygen Mixtures" AIAA J., 24: pp. 1811-1816 (1986).

14. Wolanski, P., "Grain Dust Explosion and Control," Report 1989-1990, Warsaw University of Technology, Warsaw (1990).

15. Srinath, S. R., C. W. Kauffman, J. A. Nicholls, and $M$. Sichel, "Secondary Dust Explosions," Industrial Dust Explosions, ASTM STP 958, Philadelphia, PA (1987).

16. Chang, F. L., M. Sichel, and C. W. Kauffman, "Numerical Simulation of Flame Propagation Due to Layered Combustible Dust," Fall Technical Meeting, Eastern States Section of the Combustion Institute, Gaithersburg, MD (November 1987).

17. Lee, C. O., and M. Sichel, An Investigation of the Steady Flame Propagation in a Duct., presented at the 13th International Colloquium on the Dynamics of Explosions and Reactive Systems, Nagoya, Japan (July 28-August 2, 1991).

18. Fan, B. C., and M. Sichel, "A Comprehensive Model for the Structure of Dust Detonations," pp. 1741-1750, Proceedings of the 22nd Symposium (International) on Combustion. The Combustion Institute (1989).

This paper (13e) was presented at the AIChE Spring National Meeting in Atlanta, GA on April 20, 1995. 